\title{
ARTICLE
}

\section{Measuring Family Centred Care: Working with Children and Their Parents in a Tertiary Hospital}

\author{
Linda Shields PhD FRCNA ${ }^{a}$, Abdulla A. Mamun $\mathrm{PhD}^{b}$, Sandra Pereira PhD ${ }^{c}, \mathrm{Pam}^{\mathrm{O}}$ 'Nions \\ RN BSc MN ${ }^{d}$ and Gervase Chaney MBBS FRACP
}

\begin{abstract}
a Professor of Paediatric and Child Health Nursing Curtin University and Child and Adolescent Health Service, Perth, Western Australia and Honorary Professor, Department of Paediatrics and Child Health, The University of Queensland, Brisbane, Queensland, Australia

b Associate Professor \& Statistician, School of Population Health, The University of Queensland

Brisbane, Queensland, Australia

c Biostatistical and Statistical Research Consultancy, Glasgow, Scotland

d Coordinator Paediatric Nursing Education, Princess Margaret Hospital for Children, Perth, Western Australia.

e Paediatrician and Director, Clinical Planning and Reform, Princess Margaret Hospital for Children, Child and Adolescent Health Service.Clinical Senior Lecturer, School of Paediatrics and Child Health, University of Western Australia
\end{abstract}

\begin{abstract}
Rationale and aim: Family-centred care (FCC) is widely used in paediatrics, though no rigorous evidence for it exists. A growing body of qualitative research raises concerns about FCC, and health professionals' attitudes to it. We measured attitudes to working with children and working with parents of hospitalised children held by nurses, doctors, allied health and ancillary staff at an Australian children's hospital, using a validated questionnaire with two scores, one for working with children, one for working with parents, and demographic characteristics, and compared responses.

Method: we recruited a randomized sample, and compared means of working with children and working with parents scores, using a Wilcoxon signed rank test $\mathrm{p}<0.0001$. Mean differences by categories of demographics were estimated using ANOVA and median test compared the median scores.

Results: respondents gave significantly more positive scores for working with children than parents. These were influenced by level of education, whether respondents were parents themselves, if they held senior positions, had worked with children for a long time, and held a paediatric qualification.

Conclusions: paediatric health professionals view working with children in a more positive light than working with parents. However, if FCC was being implemented effectively, given its empahsis on the whole family as the unit of care, there would be no difference between working with children or their parents. This quantiative study supports the increasing body of qualitative research which highlights problems with this model. In addition, this study provides a way to measure FCC.
\end{abstract}

\section{Keywords}

Children, family-centered care, parents, tertiary hospital

\section{Correspondence Address}

Professor Linda Shields, School of Nursing and Midwifery, Curtin University, GPO Box U1987, Perth, WA 6845, Australia. E-mail: l.shields@curtin.edu.au

Accepted for publication: 20 January 2011

\section{Introduction}

Paediatric health services world wide use family-centred care (FCC) as a model around which to plan and implement care. "Family-centred care is a way of caring for children and their families within health services which ensures that care is planned around the whole family, not just the individual child/person, and in which all the family members are recognized as care recipients” [1]. Its main element is the involvement of the parents in a child's care. The Institute of Patient and Family Centered Care [2] in the United States (US) believes it is highly successful, and lists elements of which it consists, namely recognizing the family as a constant in the child's life; facilitating parentprofessional collaboration at all levels of health care; 
honouring the racial, ethnic, cultural, and socio-economic diversity of families; recognizing family strengths and individuality and respecting different methods of coping; sharing complete and unbiased information with families on a continuous basis; encouraging and facilitating familyto-family support and networking; responding to child and family developmental needs as part of health care practices; adopting policies and practices that provide families with emotional and financial support; and designing health care that is flexible, culturally competent, and responsive to family needs.

While it is said to be widely used, Darbyshire [3] suggested that FCC is a wonderful ideal but in reality, difficult to implement because of the judgemental attitudes of nurses towards parents, resulting in the feeling that they are "parenting in public". Likewise, nurses feel they are "nursing in public". He suggested that for FCC to succeed, understanding, empathetic communication between parents and nurses was necessary.

While FCC is expressed in many policy documents in paediatric health facilities as an integral part of their philosophies, there is little evidence that FCC works, is effective, or has much impact on the delivery of care [4]. While there is no rigorous evidence that FCC works, or makes a difference to children, parents or staff, there is a growing body of qualitative research which shows consistent themes when explaining the problems with implementation of FCC [5]. These include health professionals acting as gatekeepers to parental access to admitted children [6], the use of punishment and reward if the parents do, or do not, fit the health professionals' perceptions of accepatable behaviour [7], parents' use of strategies such as bargaining with staff to ensure their needs are met [8], and exclusion of parents at the whim of the health professional [9].

Previous studies $[10,11]$ using the technique employed here found significant differences between staff's feelings about working with children and working with parents. All subject groups gave a more positive score for children than parents. While this is not surprising, given that people may choose to work in paediatrics because they enjoy working with children, it is not congruent with a FCC policy, in which the children and parents are to be treated as a single, integral unit. The aim of this current study was to determine attitudes to working with children and working with parents of hospitalised children held by staff-nurses, doctors, allied health and ancillary - at an acute care, tertiary referral, public hospital, where care is free at point of delivery and paid for through universal taxation, and which espouses a policy of family-centred care. .

\section{METHODS \\ Tool}

The tool used was the "Working with Families" questionnaire, which has been trialed in Australia, the UK,
Indonesia and Thailand [10]. It contains a range of demographic questions, plus two questions: "I find working with children ..." and "I find workingwith parents of children ...” It includes a scoring system using semantic differentials [12]. There are 10 scales each of which contains at one end an adjective and at the other its antonym. Subjects placed a cross on the line which best met how they felt about each adjective. (The adjectives were first derived from literature, interviews and trials) $[11,13]$. In trials, the scoring system consistently gained Cronbach's alpha scores of 0.8 and above. Also included was an example on how to complete the questions. The poles of the questions were changed to ensure that respondents had to make a judgement about each adjective set, in other words, some score lines went from positive to negative, while others were reversed. The only problem encountered with the questionnaires were 10 subjects who, on the first round, completed only one side of the sheet. Once this was encountered, we added a line to the bottom of each page reminding subjects to complete the other side.

\section{Sample size, recruitment and data collection}

Ethical approval was given by Curtin University Human Research Ethics Committee (HR 93/2009), plus the relevant hospital's Human Research Ethics Committee.

Using random stratified sampling from the total population of hospital staff, with a computed confidence level of $95 \%$, an estimated power of $90 \%$, and a possible non-return rate of $50 \%$, the required sample was determined to be 23 doctors, 54 nurses, 26 allied health and 44 ancillary (administration and domestic) staff. Recruitment was through the hospital internal mail, with four mail-outs of questionnaire, information sheet and return envelope, to achieve the required numbers. Consent was implied by return of the anonymous questionnaire. A response rate of $60 \%$ yielded responses from 32 doctors, 72 nurses, 39 allied health professionals and 67 ancillary staff. Towards the end of the data collection period, to meet the required number, we had to attend meetings to hand deliver and collect questionnaires, and this yielded approximately $10 \%$ of the responses. They all remained anonymous, but this may have limited the generalizability of the findings to some degree. Data were entered into SPSS as the questionnaires arrived.

\section{Data analysis}

Demographic characteristics of subjects are presented in numbers and percentages (Table 1). We conducted an exploratory analysis of the outcome variables to examine their distribution. Both outcomes - working with children and working with parents - were not normally distributed, although the scores for working with children approximated normal. For the simplicity of presentation and understanding we have presented both mean and 
median values of these outcomes by background characteristics. To compare the overall mean difference between working with children and working with parents scores, we used a non-parametric sign test (Wilcoxon signed rank test $\mathrm{p}<0.0001$ ). The mean differences by categories of background characteristics were estimated using ANOVA. Median test was used to compare the median scores of the two questions "Most of the time, I find working with children ... (score)" and "Most of the time, I find working with parents of children ... (score)”

\section{Results}

\section{Characteristics of the sample}

\section{Table 1: demographic characteristics of subjects}

\begin{tabular}{|c|c|c|}
\hline & & $\mathrm{N}(\%)$ \\
\hline \multirow{2}{*}{ Gender } & Male & $22(12.8)$ \\
\hline & Female & $150(78.2)^{\star}$ \\
\hline \multirow{4}{*}{ Age group } & 18-25 years & $11(5.8)$ \\
\hline & 26-35 years & $40(21.1)$ \\
\hline & 36-45years & $63(30.5)$ \\
\hline & Over 45 years & $96(42.6)$ \\
\hline \multirow{5}{*}{ Education level } & High school & $16(8.4)$ \\
\hline & Certificate level & $22(11.6)$ \\
\hline & Diploma & $34(17.9)$ \\
\hline & Undergraduate & $41(21.6)$ \\
\hline & $\begin{array}{l}\text { Postgraduate } \\
\text { university }\end{array}$ & 77 (40.5) \\
\hline \multirow{3}{*}{ Marital status } & Not married & $40(21.1)$ \\
\hline & Married/defacto & $129(67.9)$ \\
\hline & Widowed/divorced & 21 (11.1) \\
\hline \multirow{3}{*}{ Own children } & 0 & $60(31.6)$ \\
\hline & $1-2$ & $91(47.0)$ \\
\hline & More than 2 & $39(20.5)$ \\
\hline \multirow{4}{*}{ Occupation } & Nurse & $66(34.7)$ \\
\hline & Doctor & $31(16.3)$ \\
\hline & Allied health & $36(18.9)$ \\
\hline & Ancillary staff & $57(30)$ \\
\hline \multirow{4}{*}{$\begin{array}{l}\text { Years in } \\
\text { occupation }\end{array}$} & Under 1 year & $6(3.2)$ \\
\hline & $1-5$ years & $34(17.9)$ \\
\hline & $6-10$ years & $28(14.7)$ \\
\hline & over 10 years & $122(64.2)$ \\
\hline \multirow{2}{*}{ Level } & Senior & $153(80.5)$ \\
\hline & Junior & $57(19.5)$ \\
\hline \multirow{4}{*}{$\begin{array}{l}\text { Years in } \\
\text { current position }\end{array}$} & Under 1 year & $20(10.5)$ \\
\hline & $1-5$ years & $86(45.3)$ \\
\hline & $6-10$ years & $31(16.3)$ \\
\hline & over 10 years & $53(27.9)$ \\
\hline \multirow{4}{*}{$\begin{array}{l}\text { Years working } \\
\text { with children }\end{array}$} & Under 1 year & $7(3.7)$ \\
\hline & $1-5$ years & $39(20.5)$ \\
\hline & $6-10$ years & $37(19.5)$ \\
\hline & over 10 years & $107(56.3)$ \\
\hline \multirow{2}{*}{$\begin{array}{l}\text { Paediatric } \\
\text { qualification }\end{array}$} & Yes & $95(50)$ \\
\hline & No & $95(50)$ \\
\hline
\end{tabular}

*this question was left blank by 18 subjects
Missing data precluded the use of 20 questionnaires, leaving 190 for analysis. The sample was congruent with the characteristics of the health workforce in many developed countries. Table 1 shows that almost threequarters were over 36 years of age, $62 \%$ had university education, and another $40 \%$ had postgraduate qualifications. About $80 \%$ had partners, or had been divorced or widowed, and $68 \%$ were parents themselves. Nurses comprised $35 \%$ of the subjects, $16 \%$ were doctors, $19 \%$ allied health professionals, and 30\% ancillary staff, and over $80 \%$ had been in those occupations for longer than five years. Forty-four percent of the sample had held their current position for over five years, and 76\% had been working with children for more than five years. A high percentage (80\%) was in junior positions, and half of the subjects had a specialist paediatric qualification of some kind. Men comprised 13\% of the sample, though for an unknown reason, this one question was not answered by 18 people.

\section{Comparison of scores for working with children and working with parents}

Comparison of the two scoring questions produced significantly different results (the mean score for working with children was 4.3 ( $\mathrm{SD}=0.57$ ), and with parents 3.8 (SD $=0.66$ ). As the scoring system was set up, the highest (and most positive) score possible was a 5, while the lowest (and least positive) was 1 . Consequently, these results show that the subjects gave a more positive score for working with children than for working with their parents.

We examined influences of sample characteristics on the scores (Table 2). Age group, marital status, years in occupation, years in present position, and gender had no influence on differences between mean or median scores. However, several were statistically significant. Those with higher levels of education gave a significantly more positive score for both working with children and working with parents $(\mathrm{p}<0.001)$. People who had over two children themselves gave a more positive score for working with both children $(p=0.028)$ and parents $(p=0.027)$ than those who had fewer children, or none. A person in a senior position was more likely to give a higher score for working with children than more junior staff $(p=0.014)$ but there was no difference between senior and junior staff's scores for working with parents. Those who had worked with children for a long time gave more positive scores for working with parents than those who had not been working with children for long $(p=0.01)$, but there was no difference between them for the working with children score. Staff who held a paediatric qualification gave a higher score for working with both children $(p<0.01)$ and parents $(p=0.001)$ than those who did not have a paediatric qualification (Respondents were not required to list their specialist qualifications, but they were, in the main, postgraduate study, either postgraduate certificates, diplomas, Master or Doctor of Philosophy degrees from 
Table 2: Mean and median scores for (a) working with children and (b) working with parents, by demographic characteristics

\begin{tabular}{|c|c|c|c|c|c|c|}
\hline & & & (a) children & & (b) parents & \\
\hline & $\mathrm{N}$ & $\%$ & Mean* & Median** & Mean* & Median** \\
\hline Overall & 190 & 100 & 4.3 & 4.4 & 3.8 & 3.8 \\
\hline \multicolumn{7}{|l|}{ Age group } \\
\hline $18-25$ & 11 & 5.8 & 3.9 & 4.0 & 3.5 & 3.2 \\
\hline $26-35$ & 39 & 20.6 & 4.3 & 4.5 & 3.6 & 3.7 \\
\hline $36-45$ & 58 & 30.7 & 4.4 & 4.6 & 3.8 & 3.9 \\
\hline$>45$ & 81 & 42.9 & 4.3 & 4.4 & 3.9 & 3.9 \\
\hline$p$-value & & & 0.096 & 0.075 & 0.0235 & 0.234 \\
\hline \multicolumn{7}{|l|}{ Educational level } \\
\hline 2 & 16 & 8.6 & 4.0 & 4.2 & 3.4 & 3.1 \\
\hline 3 & 22 & 11.8 & 4.0 & 4.2 & 3.4 & 3.3 \\
\hline 4 & 34 & 18.2 & 4.0 & 4.2 & 3.8 & 3.9 \\
\hline 5 & 40 & 21.4 & 4.5 & 4.6 & 3.9 & 3.9 \\
\hline 6 & 75 & 40.1 & 4.5 & 4.5 & & \\
\hline$p$-value & & & $<0.001$ & 0.0697 & $<0.001$ & $<0.001$ \\
\hline \multicolumn{7}{|l|}{ Marital status } \\
\hline Not married & 34 & 18.5 & 4.3 & 4.4 & 3.6 & 3.7 \\
\hline Married/de facto & 129 & 70.1 & 4.3 & 4.5 & 3.8 & 3.9 \\
\hline $\begin{array}{l}\text { Widowed/divorce } \\
\text { d }\end{array}$ & 21 & 11.4 & 4.0 & 4.1 & 3.6 & 3.6 \\
\hline$p$-value & & & 0.236 & 0.054 & 0.1825 & 0.2581 \\
\hline \multicolumn{7}{|c|}{ Number of own children } \\
\hline none & 60 & 31.6 & 4.1 & 4.3 & 3.6 & 3.7 \\
\hline $1-2$ & 91 & 47.9 & 4.4 & 4.5 & 3.8 & 3.9 \\
\hline$>2$ & 39 & 20.5 & 4.4 & 4.6 & 3.9 & 4 \\
\hline$p$-value & & & 0.028 & 0.093 & 0.027 & 0.091 \\
\hline \multicolumn{7}{|c|}{ Years in occupation } \\
\hline 1 & 40 & 21.2 & 4.2 & 4.3 & 3.5 & 3.7 \\
\hline 2 & 28 & 14.8 & 4.4 & 4.6 & 3.7 & 3.9 \\
\hline 3 & 121 & 64.0 & 4.4 & 4.5 & 3.9 & 3.9 \\
\hline$p$-value & & & 0.135 & 0.089 & 0.035 & 0.279 \\
\hline \multicolumn{7}{|l|}{ Seniority } \\
\hline senior & 149 & 80.5 & 4.4 & 4.5 & 3.8 & 3.8 \\
\hline junior & 36 & 19.5 & 4.1 & 4.1 & 3.7 & 3.8 \\
\hline$p$-value & & & 0.014 & 0.021 & 0.394 & 0.827 \\
\hline \multicolumn{7}{|c|}{ Years in present position } \\
\hline$<1 \mathrm{yr}$ & 20 & 10.5 & 4.3 & 4.2 & 3.8 & 3.9 \\
\hline $1-5$ yrs & 86 & 45.3 & 4.3 & 4.5 & 3.7 & 3.9 \\
\hline 6-10yrs & 31 & 16.3 & 4.4 & 4.5 & 3.9 & 3.8 \\
\hline$>10 y r s$ & 53 & 27.9 & 4.3 & 4.4 & 3.8 & 3.8 \\
\hline$p$-value & & & 0.669 & 0.304 & 0.552 & 0.813 \\
\hline \multicolumn{7}{|c|}{ Years working with children } \\
\hline$<1 \mathrm{yr}$ & 7 & 3.7 & 4.1 & 4 & 3.6 & 3.6 \\
\hline $1-5$ yrs & 38 & 20.1 & 4.1 & 4.3 & 3.5 & 3.5 \\
\hline $6-10 \mathrm{yrs}$ & 37 & 19.6 & 4.4 & 4.5 & 3.8 & 3.9 \\
\hline$>10 y r s$ & 107 & 56.6 & 4.4 & 4.5 & 3.9 & 3.9 \\
\hline$p$-value & & & 0.068 & 0.293 & 0.01 & 0.057 \\
\hline \multicolumn{7}{|c|}{ Paediatric qualification } \\
\hline Yes & 92 & 49.2 & 4.5 & 4.5 & 3.9 & 3.9 \\
\hline No & 95 & 50.8 & 4.2 & 4.2 & 3.6 & 3.7 \\
\hline$p$-value & & & $<0.001$ & 0.005 & 0.001 & 3.7 \\
\hline \multicolumn{7}{|l|}{ Sex } \\
\hline male & 25 & 14.0 & 4.4 & 4.4 & 3.8 & 3.9 \\
\hline female & 153 & 86.0 & 4.3 & 4.4 & 3.7 & 3.8 \\
\hline p-value & & & 0.236 & 0.682 & 0.687 & 0.333 \\
\hline
\end{tabular}


across the span of nursing and allied health - a requirement for specialisation in Australia, or fellowship qualifications for doctors).

\section{Discussion}

Family-centred care is ubiquitous in policy documents in paediatric health services, and while evidence about its effectiveness is either questionable, or not available, good qualitative studies [3, 5-9] raise consistent concerns about its implementation and effectiveness. At its core is the idea of the family as the single unit of care, regardless of how that family is described, and care has to be planned around the whole family, rather than the individual sick child [1]. Effective communication is the key to FCC, and this requires trust between family members and the staff caring for them and their child [15-17]. Trust requires positive regard and respect on both sides, however, if health professionals like working with only one part of the unit to which they are giving care, then that respect and regard can be jeopardised. Our findings indicate that this group of health professionals, similarly to others where this tool has been used $[10,11]$ give a more positive score for working with children than they do for working with their parents. While some might argue that this is natural given that people may choose to work in paediatrics because they like children, it brings into question the whole premise of FCC. If FCC was truly being implemented, then there would be no significant difference between the scores for both children and their parents. A unity of care for the family cannot be achieved if one group is preferred over the other, and consequently FCC is not functioning as it should.

It is unsurprising that staff who were older, had children of their own, and held a specialist qualification in paediatrics gave higher scores for both working with children and with parents than those who were younger, did not have children and were not specialist educated. What is somewhat perplexing is the lower score for working with children given by those in senior positions in contrast to those who were junior, without a difference in working with parents' scores. Perhaps more senior staff relate better to adults than children, or have lost some of their enthusiasm for working with children. This could perhaps be teased out with qualitative methods of inquiry. However, the more positive scores for working with parents given by those who have worked in paediatrics for a long time versus their less experienced colleagues suggests that understanding of parents and the effects on their lives of a child's hospitalization is something that grows over time and with exposure.

This quantitative study contributes to the growing body of evidence that suggests problems with FCC as a model of care, and that Darbyshire may be right - that FCC is a wonderful ideal but may not be possible in practice. It is time to question the ethics [18] of continuing to implement a model that may not work.

\section{Limitations}

One question about gender was not answered by 18 people (though we do not know why). Ten other questionnaires were not included because of missing data. To reach the required sample size, we had to personally recruit subjects, and while the questionnaires remained anonymous, this may have affected the generalizability of the findings in this population. Return of the questionnaires lagged towards the end of the data collection period and we had to resort to attending sessions such as grand rounds and handing out the questionnaires. This pertained to less than $10 \%$ of the sample, but may have biased our results.

We have included a tertiary specialist paediatric health service only. Further work is underway in second level hospitals, and also in rural and remote area services. If we concatenate the data and increase the sample size, we will be better able to investigate the differences between the sub-groups, for example, between the different health professionals, thereby gaining not just a deep understanding of how different approaches and education address issues around FCC as a care delivery model, but also will provide evidence on which we can tailor education packages for each group.

\section{Implications for research}

1. Further quantitative examination of FCC should be undertaken to prove (or disprove) its effectiveness as a model of care ${ }^{4}$.

2. This study shows problems with FCC in an acute care tertiary paediatric hospital, but children are cared for in a wide range of settings. The study is being repeated in two secondary hospitals and two rural hospitals at present, and could be undertaken in a variety of settings, for example, community health.

3. Research is needed to develop, implement and trial an alternative model of care.

\section{Implications for practice}

One must query the ethics of continuing a model of care that is of doubtful efficacy, for which little rigorous evidence exists, and which is more and more being challenged by the findings from solid qualitative research. A large amount of funding is used to support a model that may not be working and may not be the best way of delivering care. An alternative approach is urgently needed. 


\section{Acknowledgements}

We thank all the staff who completed the questionnaire, and Ms Tessie Zappia who assisted with data collection, Ms Marie Baxter who assisted with securing funding and Channel 7 Telethon who partly funded the study.

\section{References}

[1] Shields, L., Pratt, J., Hunter, J. (2006) Family-centred care: a review of qualitative studies. Journal of Clinical Nursing 15(10), 1317-1323

[2] Institute for Patient- and Family-Centered Care (2010) Family-centered care: Frequently asked questions. What is patient and family centered care? Institute for FamilyCentred Care, Bethesda, Maryland. Available at: http://www.ipfcc.org/faq.html (accessed 22 November 2010).

[3] Darbyshire, P. (1994) Living With a Sick Child in Hospital: The Experiences of Parents and Nurses. London: Chapman \& Hall.

[4] Shields, L., Pratt, J., Davis, L.M., Hunter, J. (2007) Family-centred care for children in hospital. Cochrane Database of Systematic Reviews, Issue 1. Art. No.: CD004811. DOI: 10.1002/14651858.CD004811.pub2.

[5] MacKean, G.L., Thurston, W.E., Scott, C.M. (2005) Bridging the divide between families and health professionals' perspectives on family-centred care. Health Expectations: an International Journal of Public Participation in Health Care and Health Policy 8(1), 7485.

[6] Aein, F., Alhani, F., Mohammadi, E., Kazemnejad, A. (2009) Parental participation and mismanagement: a qualitative study of child care in Iran. Nursing and Health Science; 11, 221-7.

[7] Coyne, I. (2008) Disruption of parent participation: Nurses strategies to manage parents on children's wards. Journal of Clinical Nursing 17, 3150-3158.

[8] Kristensson-Hallström, I., \& Elander, G. (1997) Parents' experience of hospitalization: Different strategies for feeling secure. Pediatric Nursing 23, 361-376.

[9] Coyne, I., Cowley, S. (2007) Challenging the philosophy of partnership with parents: A grounded theory study. International Journal of Nursing Studies 44, 893904.

[10] Shields, L. (1999) A comparative study of the care of hospitalized children in developed and developing countries. PhD Thesis, University of Queensland.

[11] Aggarwal, S., Chadha, P., Kalia, S., Richardson, S., Winterbottom, L., Shields, L. (2009) Perceptions of family-centred care: a UK pilot study of the Shields and Tanner questionnaires. Neonatal, Paediatric and Child Health Nursing 12(2), 25-29

[12] Osgood, C.E., Suci, G.J., \& Tannenbaum, P.H. (1957) The measurement of meaning. Urbana: University of Illinois Press.

[13] Shields, L. (2007) Using semantic differentials in fieldwork. Journal of Evaluation in Clinical Practice. 7, 116-9

[14] Siegel, S., Castellan, N.J. (1988) Nonparametric statistics for the behavioural sciences $2^{\text {nd }}$ edn. New York: McGraw-Hill Book Company.

[15] Shields, L., Hallström, I., O’Callaghan, M. (2003) An examination of the needs of parents of hospitalized children: comparing parents' and staff's perceptions. Scandinavian Journal of Caring Sciences 17, 176-184.

[16] Shields, L., Hunter, J., Hall, J. (2004) Parents' and staff's perceptions of parental needs during a child's admission to hospital: an English perspective Journal of Child Health Care 8(1), 9-33.

[17] Shields, L., Young, J., McCann, D. (2008) The needs of parents of hospitalized children in Australia. Journal of Child Health Care 12(1), 60-75.

[18] Shields, L. (2010) Questioning family-centred care. Journal of Clinical Nursing. 19, 2629-2638. 